\title{
Anterograde effects of a single electroconvulsive shock on inhibitory avoidance and on cued fear conditioning
}

M.G.M. Oliveira,

O.F.A. Bueno and E.B. Gugliano
Departamento de Psicobiologia, Universidade Federal de São Paulo, Escola Paulista de Medicina, São Paulo, SP, Brasil

\section{Correspondence \\ M.G.M. Oliveira \\ Rua Napoleão de Barros, 925 \\ 04024-002 São Paulo, SP \\ Brasil \\ Fax: 55 (011) 572-5092 \\ E-mail: mgabi@ psicobio.epm.br}

Research supported by CNPq and AFIP. Publication supported by FAPESP.

An abstract of this paper was presented at the 26th Annual Meeting of the Society for Neuroscience, Washington, DC, USA, 1996

Received March 10, 1997 Accepted May 28, 1998

\section{Abstract}

A single electroconvulsive shock (ECS) or a sham ECS was administered to male 3-4-month-old Wistar rats 1, 2, and $4 \mathrm{~h}$ before training in an inhibitory avoidance test and in cued classical fear conditioning (measured by means of freezing time in a new environment). ECS impaired inhibitory avoidance at all times and, at 1 or $2 \mathrm{~h}$ before training, reduced freezing time before and after re-presentation of the ECS. These results are interpreted as a transient conditioned stimulus (CS)-induced anxiolytic or analgesic effect lasting about $2 \mathrm{~h}$ after a single treatment, in addition to the known amnesic effect of the stimulus. This suggests that the effect of anterograde learning impairment is demonstrated unequivocally only when the analgesic/anxiolytic effect is over (about $4 \mathrm{~h}$ after ECS administration) and that this impairment of learning is selective, affecting inhibitory avoidance but not classical fear conditioning to a discrete stimulus.

Patients who are subjected to electroconvulsive therapy present transient amnesia. This amnesia, however, seems to be of a selective nature, affecting performance in tasks that assess declarative memory, but not affecting performance in procedural memory tests (1). Recently, Bueno and collaborators (2) showed that daily administration of electroconvulsive shock (ECS) for 7 days impairs performance of rats in an inhibitory avoidance task, but does not affect fear conditioned to a discrete stimulus (a sound previously paired with a footshock), when the animals are simultaneously trained in both tasks $24 \mathrm{~h}$ after the last ECS. This result shows that, as in human beings, the nature of the learning task is a determining factor for these effects.

\section{Key words}

- Electroconvulsive shock

- Memory

- Cued fear conditioning

- Inhibitory avoidance

- Anxiolytic effect

- Analgesic effect
A single ECS administered immediately after training produces retrograde amnesia in rodents (3). Anterograde deficits have been reported when ECS is administered $1 \mathrm{~h}$ before training in inhibitory avoidance, but not after an interval of $24 \mathrm{~h}$ (4-7). The objective of the present study was to investigate the effect of a single ECS administered at different time intervals before the simultaneous training in inhibitory avoidance and cued fear classical conditioning, tasks that were shown to be selectively affected by the repeated ECS regimen (2).

Male Wistar rats, three months old at the beginning of the experiment, from the animal facility of the Department of Psychobiology of the Universidade Federal de São Paulo were used. 
The experiment was performed in an inhibitory avoidance box and in an open-field. The inhibitory avoidance box consisted of two boxes, both measuring $30 \times 21 \times 30 \mathrm{~cm}$, separated by a sliding door. The safe compartment (A) was painted white and the shock compartment (B) was painted black. A metal grid (each rod measuring $0.4 \mathrm{~cm}$ in diameter and spaced $1.2 \mathrm{~cm}$ from the next one) on the floor of the black compartment was connected to a Grason-Stadler Model 700 shock generator, through which footshocks of 1 $\mathrm{mA}$ and 1-s duration could be delivered.

Groups of rats received 1 ECS $(80 \mathrm{~mA}$, 0.2-s duration) $4 \mathrm{~h}$ (ECS4), $2 \mathrm{~h}$ (ECS2), or 1 $\mathrm{h}$ (ECS1) before the beginning of training, through ear clips to which they were previously habituated. Control animals (CON) underwent a similar treatment except that no ECS was released. An open-field arena (80 $\mathrm{cm}$ in diameter and $30 \mathrm{~cm}$ high) was also used. Each apparatus was set up in a different room. A buzzer placed on the outer side of the avoidance apparatus or above the open-field arena could deliver a weak tone (ca. $90 \mathrm{~dB}$ ) of 1-s duration, used as conditioned stimulus (CS). One, two or four hours after ECS administration each rat was placed in compartment A with the door closed. After $10 \mathrm{~s}$ the door was opened, and as soon

Figure 1 - Effects of ECS administered $1 \mathrm{~h}$ (ECS1), $2 \mathrm{~h}$ (ECS2), and $4 \mathrm{~h}$ (ECS4) prior to training on retention latency of inhibitory avoidance. ${ }^{*} \mathrm{P}<0.05$ compared to control (CON) group (MannWhitney U-test).

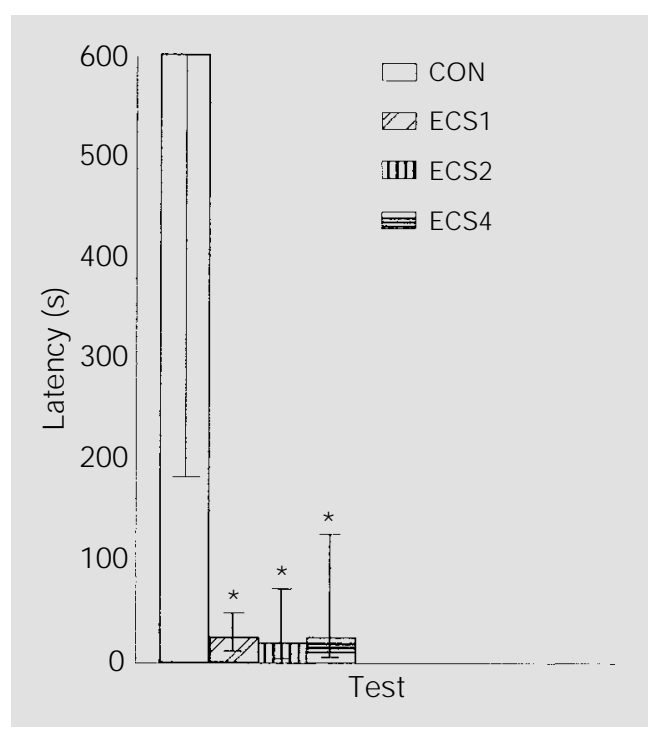

as the animal stepped into the black compartment, it was closed again. A tone used as conditioned stimulus sounded for $1 \mathrm{~s}$, after which a footshock, used as an unconditioned stimulus, was immediately delivered. The tone-footshock pairing was repeated 5 times $15 \mathrm{~s}$ apart. After this procedure, the rat was removed from the apparatus. Twenty-four hours later one half of the rats were placed in the open field for $8 \mathrm{~min}$, where freezing time (body immobility and absence of whisker movement associated with sniffing) was measured. During the 4th min of exposure to the apparatus, the CS was presented 5 times at 15-s intervals beginning at the end of the 3rd min. Freezing time was recorded during the first $3 \mathrm{~min}$ (before CS) and during the final 5 min (after CS). The other half of the animals were tested in the inhibitory avoidance task. Each rat was placed in compartment A of the avoidance apparatus, and after the door was opened the time (in seconds) it took to step into compartment B with all four paws (test latency) was recorded. If the animal did not step through within $600 \mathrm{~s}$ it was returned to its home cage and a latency of $600 \mathrm{~s}$ was assigned to it.

Figure 1 shows the performance of animals in the inhibitory avoidance task. Groups ECS1 $(\mathrm{N}=13), \operatorname{ECS} 2(\mathrm{~N}=12)$ and ECS4 (N $=14)$ were different from controls $(\mathrm{N}=16)$ (Kruskal-Wallis: $\mathrm{H}=11.43, \mathrm{P}<0.01$; MannWhitney: CON x ECS1: $\mathrm{U}=38.5, \mathrm{P}<0.01$; CON x ECS2: $\mathrm{U}=40.5, \mathrm{P}<0.01$; $\mathrm{CON} x$ ECS4: $\mathrm{U}=54.0, \mathrm{P}<0.01)$.

Mean freezing time in the open-field arena is presented in Figure 2. Two-way ANOVA showed that there was a sound effect $\left(\mathrm{F}_{(1.63)}\right.$ $=421.1, \mathrm{P}<0.0001)$ and a group effect $\left(\mathrm{F}_{(3.63)}\right.$ $=3.56, \mathrm{P}=0.019)$; however, group $\mathrm{x}$ sound interaction was not statistically significant $\left(F_{(3.63)}=2.16, P=0.10\right)$. The Newman-Keuls test showed that groups ECS1 $(\mathrm{N}=19)$ and ECS2 $(\mathrm{N}=18)$, but not ECS4 $(\mathrm{N}=14)$, were different from the controls $(\mathrm{N}=16)(\mathrm{P}<0.05)$.

Previous studies in our laboratory have demonstrated that the effects of repeated 
ECS administration is dissociative, affecting an inhibitory avoidance task but preserving a cued conditioned fear response. The freezing response to the tone is a genuine conditioned response, since footshock alone on the previous day does not induce a strong fear reaction even though it enhances sensitization to the novel enviromment (the openfield), as assessed by freezing time before the tone (2). A similar dissociation was reported between the effects of hippocampal and amygdala lesions on contextual learning (presumably a kind of learning akin to inhibitory avoidance) and cued fear learning $(8,9)$.

Dissociation between the two tasks was also obtained after administration of a single ECS before training but only after the interval of $4 \mathrm{~h}$, at which time the inhibitory task was impaired and the cued fear response was spared. ECS administered 1 or $2 \mathrm{~h}$ before training reduced freezing time in the openfield. Any treatment that has an effect on cued conditioned fear should reduce only the freezing following presentation of the CS (the sound, previously paired with footshock). This was not the case, since there was no sound $\mathrm{x}$ group interaction, i.e., freezing was not disproportionately reduced after the sound. This fact suggests that reduction in freezing time is due to the reduction in generalized fear, i.e., freezing not conditioned to the tone. One possibility to explain the generalized freezing response decrement is that a single ECS may have an anxiolytic effect on training when administered shortly before the training session. According to this hypothesis, the reduction in generalized fear observed during testing would be due to the anxiolytic effect of ECS operative during training. Nevertheless, ECS is known to produce potent analgesia $(10,11)$ and therefore a reduced shock sensitivity induced by ECS could be responsible for its apparent fearreducing effect. When administered $4 \mathrm{~h}$ prior to training, ECS did not produce changes in freezing time, which shows that the putative analgesic/anxiolytic effect is transient, last-

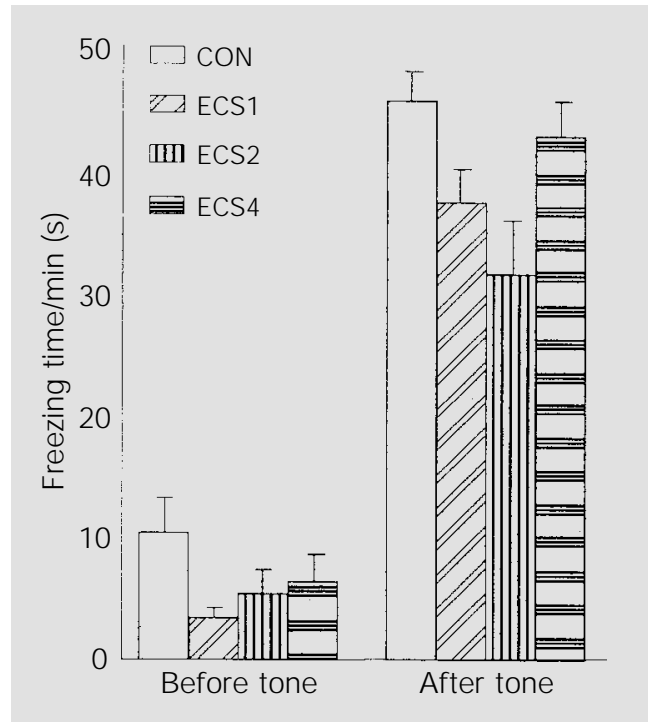

Figure 2 - Effects of ECS administered $1 \mathrm{~h}$ (ECS1), $2 \mathrm{~h}$ (ECS2), and $4 \mathrm{~h}$ (ECS4) prior to training on freezing reaction (mean \pm SEM) prior to and following the conditioned stimulus (sound). Groups ECS1 and ECS2, but not ECS4, were different from control (CON) (Newman-Keuls post hoc test for group effect following two-way ANOVA, $\mathrm{P}<0.05$ ). ing at least $2 \mathrm{~h}$ but less than $4 \mathrm{~h}$. This seems to contradict the analgesic explanation, however, since the time course of the ECS-induced analgesic effect seems to be shorter than $30 \mathrm{~min}(12,13)$. Further investigation assessing footshock sensitivity after ECS administration can settle this issue.

In the inhibitory avoidance test, the 3 groups that underwent ECS treatment presented a reduction of latency to enter the dark box, which is in accordance with previous reports $(4,5)$ showing that a single ECS administration, 1 to $4 \mathrm{~h}$ before training, impairs acquisition of this type of task. The question raised by our results is that the performance reduction shortly after ECS administration could be interpreted as a transient analgesic or anxiolytic effect. ECS administered $4 \mathrm{~h}$ before training affected the performance of the animals in the inhibitory avoidance, but did not alter freezing time in the open field, i.e., it had no effect on non-conditioned or conditioned fear. In this case, we may state that the performance reduction is due to an anterograde effect of ECS on learning, selectively affecting inhibitory avoidance, rather than to other effects present at the time of training. Thus, the anterograde learning effect is unequivocally demonstrated only when the analgesic/anxiolytic effect is over (about $4 \mathrm{~h}$ after ECS administration). 


\section{References}

1. Squire LR, Cohen NJ \& Zouzounis JA (1984). Preserved memory in retrograde amnesia: sparing of a recently acquired skill. Neuropsychologia, 22: 145-152.

2. Bueno OFA, Oliveira MGM, Pomarico AC \& Gugliano EB (1993). A dissociation between the proactive ECS effects on inhibitory avoidance and on classical fear conditioning. Behavioral and Neural Biology, 81: 180-185.

3. McGaugh J L (1966). Time-dependent process in memory storage. Science, 153: 1351-1358.

4. Kopp R, Bohdanecky $Z \&$ \& arvik ME (1967). Proactive effect of ECS on stepthrough performance of naïve and punished mice. J oumal of Comparative and Physiological Psychology, 64: 22-25.

5. Kopp R, Bohdanecky $Z \&$ \& arvik ME (1968). Proactive effect of electroconvulsive shock (ECS) on one-trial learning in mice. J ournal of Comparative and Physiological Psychology, 65: 514-517.

6. Lerer B, Stanley M, Keegan M \& Altman $H$ (1986). Proactive and retroactive effects of repeated electroconvulsive shock on passive avoidance retention in rats. Physiology and Behavior, 36: 471-475.

7. Zerbolio DJ (1969). The proactive effect of electroconvulsive shock on memory storage: with and without convulsion. Communications in Behavioral Biology, 4: 23-27.

8. Kim JJ \& Fanselow MS (1992). Modalityspecific retrograde amnesia of fear. Science, 256: 675-677.

9. Phillips RG \& LeDoux J E (1992). Differential contribution of amygdala and hippocampus to cued and contextual fear conditioning. Behavioral Neuroscience, 106: 274-285.

10. Holaday J W \& Belenky GL (1980). Opiate- like effects of electroconvulsive shock in rats: differential effect of naloxone on nociceptive measures. Life Sciences, 27: 1929-1938.

11. Urca G, Yitzhaky J \& Frenk H (1981). Different opioid systems may participate in post-electroconvulsive shock (ECS) analgesia and catalepsy. Brain Research, 219: 385-396.

12. Furui T, Harty GJ \& Yaksh TL (1986). Studies on the effects of opioid, noradrenergic and serotonergic antagonists on the antinociceptive effects of electroconvulsive shock. Brain Research, 367: 162-168.

13. J ackson HC \& Nutt DJ (1991). Investigation of the different types of opioid receptor involved in electroconvulsive shockinduced antinociception and catalepsy in the rat. J oumal of Pharmacy and Pharmacology, 43: 640-643. 